\title{
Increased frequency of $E S R I$ mutation in metastatic breast cancer by dosing selective estrogen receptor modulator followed by aromatase inhibitor
}

\author{
KAORU TAKESHIMA ${ }^{1}$, TETSU HAYASHIDA ${ }^{2}$, HINAKO MAEDA ${ }^{2}$, AYAKO NAKASHOJI $^{2}$, \\ TAKAMICHI YOKOE ${ }^{2}$, TOMOKO SEKI ${ }^{2}$, MAIKO TAKAHASHI $^{2}$ and YUKO KITAGAWA ${ }^{2}$ \\ ${ }^{1}$ Department of Surgery, Saitama City Hospital, Saitama 336-0911; \\ ${ }^{2}$ Department of Surgery, Keio University School of Medicine, Tokyo 160-8582, Japan
}

Received December 25, 2019; Accepted April 30, 2020

DOI: 10.3892/ol.2020.11669

\begin{abstract}
In several recent studies on metastatic breast cancer (MBC), ligand binding domain mutations of the estrogen receptor, which is coded by the ESRI gene, were induced by long-term endocrine therapy and resulted in acquired endocrine therapy resistance and poor outcomes. Knowledge of the association between the development of ESRI mutation and the clinicopathologic features may guide the decision-making process of metastatic breast cancer treatment, including endocrine therapy. The aim of the present study was to evaluate the association between the development of ESR1 mutation and the clinicopathologic characteristics of patients with MBC. To evaluate the association between the development of ESR1 mutation and clinicopathologic features, a cohort of 22 patients with $\mathrm{MBC}$ were retrospectively analyzed using next generation sequencing. In 14 of 22 patients, four mutations were detected on the metastatic site, including Tyr537Ser, Glu542Asp, Leu536Arg and Arg548Cys. Univariate analysis demonstrated that the duration of aromatase inhibitor and selective estrogen receptor modulator treatment, as well as the age of treatment initiation for early-stage breast cancer, were significantly associated with the development of ESRI mutation. ESRI mutation was identified in all five patients who
\end{abstract}

Correspondence to: Dr Tetsu Hayashida, Department of Surgery, Keio University School of Medicine, 35 Shinanomachi, Shinjuku, Tokyo 160-8582, Japan

E-mail: tetsu@keio.jp

Abbreviations: AI, aromatase inhibitor; ER, estrogen receptor; ET, endocrine therapy; LBD, ligand-binding domain; MBC, metastatic breast cancer; NGS, next generation sequencing; OS, overall survival; PFS, progression-free survival; PgR, progesterone receptor; SERD, selective estrogen receptor degrader; SERM, selective estrogen receptor modulator

Key words: aromatase inhibitor, endocrine therapy resistance, ESR1 mutation, metastatic breast cancer, selective estrogen receptor modulator received selective estrogen receptor modulators in the adjuvant setting followed by aromatase inhibitors in the metastatic setting, as well as in two of the three patients who received no selective estrogen receptor modulators in adjuvant setting followed by aromatase inhibitors in the metastatic setting. In conclusion, the results of the present study suggested that administrating adjuvant selective estrogen receptor modulator followed by aromatase inhibitor for metastasis may increase the frequency of ESRI mutation.

\section{Introduction}

Estrogen receptor (ER), which is encoded in the estrogen receptor 1 (ESRI) gene, belongs to the nuclear hormone receptor family (1) and the ESRI gene is located on chromosome 6 (6q25.1) and includes 8 exons (2). ER is expressed in over $60 \%$ of breast cancers (3) and consists of two activation function domains, AF1/2, a DNA binding domain and a hinge domain, and a ligand-binding domain (LBD) (4). ER functions as a ligand-dependent transcription factor, and ligand binding to the LBD leads to activation of gene transcription, resulting in breast cancer progression $(5,6)$. Adjuvant endocrine therapy (ET) inhibiting ER-induced breast cancer progression reduces local recurrence and mortality in patients with ER-positive early breast cancer $(3,7)$. Similarly, ET with aromatase inhibitors (AIs), selective estrogen receptor modulators (SERMs) and selective estrogen receptor degrader (SERD) serves an important role in the treatment of patients with ER-positive metastatic breast cancer (MBC) (1). However, a number of patients with ER-positive MBC have intrinsic ET resistance or acquire resistance following response to ET, and eventually almost all patients with MBC develop resistance to ET (8). ET resistance mechanisms include upregulation of the steroid receptor coactivator-3, human epidermal growth factor 2 (HER2) or nuclear factor $\kappa \mathrm{B}$ and activator protein 1 (9-11). Cyclin D1 gene amplification frequently occurs in ER-positive breast cancer and overexpression of Cyclin D1 leads to ET resistance in ER-positive breast cancer $(12,13)$. A number of previous studies indicated that LBD mutations (i.e., Tyr537Ser and Asp538Gly) in ESRl gene were induced by long-term ET and resulted in acquired ET resistance independently of 
estrogen levels, as well as poor outcomes in patients with MBC (14-18). Knowledge of the associations between the development of ESRI mutation and patient clinicopathological characteristics may guide the decision-making process of MBC treatment, including ET. The aim of the present study was to evaluate the association between the development of ESR1 mutation and the clinicopathologic characteristics of patients with MBC.

\section{Materials and methods}

Clinical samples. Patients with MBC who had received treatment for primary ER-positive breast cancer and were followed-up at Keio University Hospital between January 2012 and December 2015 were enrolled in this study; during that period, 24 biopsy samples from the metastatic sites were available for analysis. The inclusion and exclusion criteria were as follows: Metastatic samples with $\geq 100 x$ sequence coverage on next generation sequence (NGS) were included, while samples $<100 x$ sequence coverage were excluded from the present study. Metastatic samples were evaluated by NGS, with a level of sequence coverage of $>100$-fold, to detect the LBD mutations of the ESR1 gene and validate these ER mutations in patients with MBC. The 24 metastatic site samples were assessed, and two were excluded from NGS due to low sequence coverage. Thus, a total of 22 metastatic samples were evaluated in the present study. The Allred score was used to assess the receptor status at metastatic sites (19). The clinical data, including the ET administered and clinical outcomes, were obtained from all patients. The study protocol and the opt-out informed consent procedure were approved by the Ethics Review Board of Keio University Hospital and conformed to the Declaration of Helsinki. Informed consent was acquired from the patients by opt-out procedure prior to the beginning of the study.

DNA extraction. Using the biopsy samples from the MBC patients, unstained $10-\mu \mathrm{m}$ thick formalin-fixed paraffin embedded (FFPE) blocks were obtained. Tumor tissue was collected from the two blocks and placed in $1.5 \mathrm{ml}$ microtubes. Genomic DNA was extracted using a NucleoSpin DNA FFPE XS isolation kit (Takara Bio, Inc.). DNA was quantified by Qubit 3.0 Fluorometer using the Qubit dsDNA HS Assay kit (Thermo Fisher Scientific, Inc.), according to the manufacturer's instructions, and adjusted to a final concentration of $20 \mathrm{ng} / \mu \mathrm{l}$.

Target amplification and sequencing. For target amplification of the mutation hotspot in the LBD of the ESRl gene, PCR of the extracted genomic DNA was performed using custom primers and ligating Illumina read1 and read 2 sequences (Illumina, Inc.). The second PCR primer pairs were used to ligate the Illumina adaptor and index sequence to the first PCR products. The target amplification PCR primer sequences were as follows: Forward, 5'-ACACTCTTTCCCTACACG ACGCTCTTCCGATCTGGCTCGGGTTGGCTCTAAA-3' and reverse, 5'-GTGACTGGAGTTCAGACGTGTGCTCTT CCGATCTTAGTGGGCGCATGTAGGC-3'. The second PCR primer sequences were as follows: Forward, 5'-AAT GATACGGCGACCACCGAGATCTACACTCTTTCCCTA CACGACGCTCTTCCGATCT-3' and reverse, 5'-CAAGCA
GAAGACGGCATACGAGATNNNNNNGTGACTGGAGTT CAGACGTGTGCTCTTCCGATCT-3' (NNNNNN: Index sequence). These sequences refer to ESRI. Fig. 1 demonstrates the target amplification PCR primer pairs and the second PCR primer pairs. In a $10-\mu 1$ reaction buffer that contained $5 \mathrm{mM}$ deoxynucleotide triphosphate mix, $0.25 \mu \mathrm{M}$ of each custom made primer and $0.2 \mu$ l Herculase II Fusion DNA polymerase (Agilent Technologies, Inc.), $20 \mathrm{ng}$ of the genomic DNA underwent amplification for 20 cycles of $10 \mathrm{sec}$ at $98^{\circ} \mathrm{C}$, $30 \mathrm{sec}$ at $55^{\circ} \mathrm{C}$ and $30 \mathrm{sec}$ at $72^{\circ} \mathrm{C}$. The amplicon, which was $1 \mu \mathrm{l}$ of the PCR product diluted 10 times, was marked in a second PCR with molecular indices for Illumina Miseq, using TrueSeq DNA HT Sample Kits (Illumina, Inc.). The second amplification was performed as aforementioned.

DNA libraries were formed from the second PCR products, which were purified using the Agencourt AMPure XP reagent, according to the manufacturer's instructions (Beckman Coulter, Inc.) and quantified by the method described above. The library was sequenced on the Miseq instrument on the paired-end mode with the Miseq Reagent kit v3 (Illumina, Inc.) according to the manufacturer's instructions. The sequence data were mapped to the reference human genome ( $h g 19)$ using BWA aligner [version 0.7.16a-r1181; (20)], SAMtools [version 1.6; (21)] and Picard (http://sourceforge.net/projects/picard). Local alignment and quality score calibration were performed according to the Genome Analysis Toolkit (GATK) best practice (22). Single nucleotide variants were called using the 'HaplotypeCaller' tool in GATK. All variants were annotated using snpEff (23) and reviewed by the Integrative Genomics Viewer (24). Variants were filtered using dbSNP_138 (http://www.ncbi.nlm.nih.gov/projects/SNP). GRCh37.75 in the Ensembl genome browser (http://www.ensembl.org) was used as the reference genome of annotation.

Statistical analysis. Statistical analyses were performed with R commander (version 2.4-1) based on R (version 3.3.3; http://cran.r-project.org/) and with EZR, which is a modified version of the $\mathrm{R}$ commander (25). Among the continuous variables, age followed a normal distribution as determined by the Shapiro-Wilk test; thus, it was presented as the mean \pm standard deviation and analyzed using the independent two-sample Student's t-test. The other continuous variables were expressed as the median (range) and evaluated by the Wilcoxon rank sum test. Categorical variables were analyzed by the Fisher's exact test. The correlation between two continuous variables was evaluated by calculating Spearman's rank correlation coefficient. $\mathrm{P}<0.05$ was considered to indicate a statistically significant difference.

\section{Results}

Baseline characteristics and detection of ESRI mutations in patients with $M B C$. The baseline characteristics of the 22 patients with MBC are presented in Table I. The mean age of the patients at the start of treatment was 54 years. The TNM stage of primary breast cancer was I in 7 (32\%) patients, IIA in $9(41 \%)$ patients, IIB in $4(18)$ patients, IIIB in $1(5 \%)$ patient and IV in $1(5 \%)$ patient. The histologic type of primary lesion was invasive ductal carcinoma in $21(95 \%)$ patients and invasive lobular carcinoma in $1(5 \%)$ patient. The Progesterone receptor 


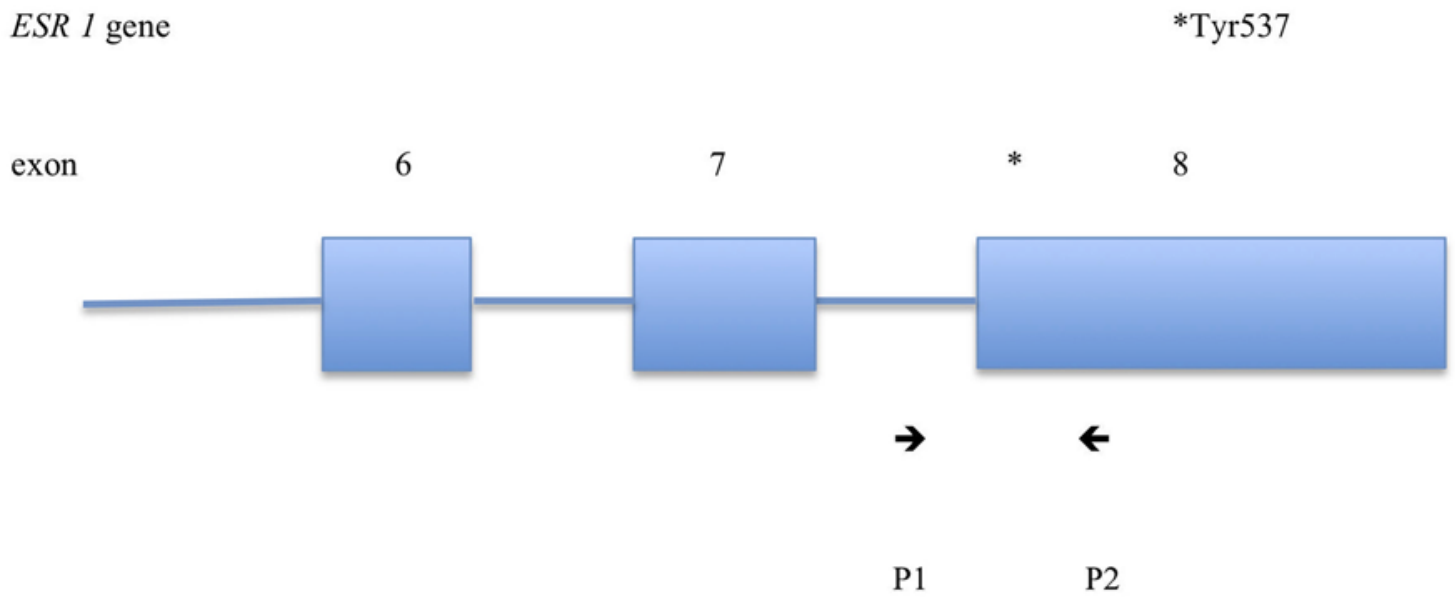

Target amplification PCR primer

P1: 5'-ACACTCTTTCCCTACACGACGCTCTTCCGATCTGGCTCGGGTTGGCTCTAAA-3'

P2: 5'-GTGACTGGAGTTCAGACGTGTGCTCTTCCGATCTTAGTGGGCGCATGTAGGC-3'

Second PCR primer

5'-AATGATACGGCGACCACCGAGATCTACACTCTTTCCCTACACGACGCTCTTCCGATCT-3'

5'-CAAGCAGAAGACGGCATACGAGATNNNNNNGTGACTGGAGTTCAGACGTGTGCTCTTCC

GATCT-3,

NNNNNN :Index sequence

Figure 1. The primer sequences used for target amplification.

$(\mathrm{PgR})$ and HER2 status of the primary tumor was positive in $21(95 \%)$ and four (18\%) patients, respectively; HER2 status was unknown in one case.

As presented in Table II, ESRI mutation at the metastatic site was observed in $14(64 \%)$ of the 22 patients. A total of four ESR1 mutations were identified including 1610A $>$ C, 1626G $>$ T, $1607 \mathrm{~T}>\mathrm{G}$ and $1642 \mathrm{C}>\mathrm{T}$, which led to amino acid mutations Tyr537Ser in 10 (45\%) patients, Glu542Asp in $2(9 \%)$ patients, Leu536Arg in $1(5 \%)$ patient and Arg548Cys in $1(5 \%)$ patient, respectively. The range of allele mutation frequency was $2-99 \%$.
ESR1 mutation and the clinical characteristics of patients with $M B C$. The ER Allred score of the primary tumor was positive by immunohistochemical staining in all 22 patients prior to this study (19). Of the 22 samples, 21 and 17 were positive for ER and PgR, respectively (unavailable in 1 sample). The metastatic biopsy site was the liver in 7 (32\%) patients, skin in $6(27 \%)$ patients, lymph node in $4(18 \%)$ patients, lung in $3(14 \%)$ patients, bone in $1(5 \%)$ patient and muscle in $1(5 \%)$ patient.

Among the 22 patients with MBC, including one with stage IV cancer, 19 patients received at least one ET agent 
Table I. The baseline characteristics of 22 patients with metastatic breast cancer.

\begin{tabular}{lc}
\hline Variable & Number of patients (\%) \\
\hline Age at the start of treatment, years & $54 \pm 13$ \\
TNM stage of primary breast cancer & \\
I & $7(32)$ \\
IIA & $9(41)$ \\
IIB & $4(18)$ \\
IIIA & $0(0)$ \\
IIIB & $1(5)$ \\
IIIC & $0(0)$ \\
IV & $1(5)$ \\
Histological type & \\
Invasive ductal & $21(95)$ \\
Invasive lobular & $1(5)$ \\
PgR status of the primary tumor & \\
Positive & $21(95)$ \\
Negative & $1(5)$ \\
HER2 status of the primary tumor & \\
Positive & $4(18)$ \\
Negative & $17(77)$ \\
Unknown & $1(5)$ \\
\hline
\end{tabular}

TNM, Tumor-Node-Metastasis; PgR, progesterone receptor.

prior to the metastatic site biopsy; ESRI mutation was detected in 13 patients, but it was not detected in 6 patients. Of the 21 patients with MBC (excluding the patient with stage IV MBC), 16 patients received ET in an adjuvant setting, which was complete in 10 cases and incomplete in 6 cases. An incomplete adjuvant setting was defined as recurrence of breast cancer within five years of treatment. Among the 16 patients who received ET in the adjuvant setting, ESRI mutation was detected in 2 of 6 patients who received AIs, in 8 of 9 patients who received SERMs and in 1 patient who received both AI and SERM. Between the recurrence and the biopsy of the metastatic site, 7 of 8 patients who received AIs developed ESR I mutation. ESRI mutation was identified in all 5 patients who received SERM in the adjuvant setting followed by $\mathrm{AI}$ in the metastatic setting, as well as in 2 of 3 patients who did not receive SERM in adjuvant setting followed by AI in the metastatic setting. In addition, 7 of 8 patients who had no ESR 1 mutation did not receive any ET for metastasis. The patient with stage IV MBC, who was administered AIs until the biopsy of the metastatic site, developed ESRI mutation. These results are presented in Table III.

Association between ESR1 mutation and clinicopathological characteristics in 22 patients with $M B C$. Considering the total period between the beginning of treatment and the biopsy of the metastatic site in 22 patients with MBC, the SERM intake period was significantly longer in patients with ESRI mutation compared with that in patients with wild-type ESRI (26 vs. 0 months; $\mathrm{P}=0.01)$. The total interval of treatment with $\mathrm{AI}$ and
Table II. Cases of metastatic breast cancer with estrogen receptor 1 mutations $(\mathrm{n}=14)$.

\begin{tabular}{cccc}
\hline Case no. & Mutation & $\begin{array}{c}\text { Amino acid } \\
\text { change }\end{array}$ & $\begin{array}{c}\text { Mutation } \\
\text { frequency, } \%\end{array}$ \\
\hline 1 & $1610 \mathrm{~A}>\mathrm{C}$ & Tyr537Ser & 96 \\
2 & $1610 \mathrm{~A}>\mathrm{C}$ & Tyr537Ser & 99 \\
3 & $1610 \mathrm{~A}>\mathrm{C}$ & Tyr537Ser & 79 \\
4 & $1610 \mathrm{~A}>\mathrm{C}$ & Tyr537Ser & 15 \\
5 & $1610 \mathrm{~A}>\mathrm{C}$ & Tyr537Ser & 87 \\
6 & $1610 \mathrm{~A}>\mathrm{C}$ & Tyr537Ser & 22 \\
7 & $1610 \mathrm{~A}>\mathrm{C}$ & Tyr537Ser & 36 \\
8 & $1642 \mathrm{C}>\mathrm{T}$ & Arg548Cys & 2 \\
9 & $1610 \mathrm{~A}>\mathrm{C}$ & Tyr537Ser & 18 \\
10 & $1610 \mathrm{~A}>\mathrm{C}$ & Tyr537Ser & 58 \\
11 & $1610 \mathrm{~A}>\mathrm{C}$ & Tyr537Ser & 21 \\
12 & $1607 \mathrm{~T}>\mathrm{G}$ & Leu536Arg & 68 \\
13 & $1626 \mathrm{G}>\mathrm{T}$ & Glu542Asp & 15 \\
14 & $1626 \mathrm{G}>\mathrm{T}$ & Glu542Asp & 20 \\
\hline
\end{tabular}

AI/ SERM was not significantly different between patients with ESR I mutation and those without ESRI mutation $(\mathrm{P}=0.92$ and $\mathrm{P}=0.13$, respectively; Table IV).

Considering the treatment period from recurrence to biopsy of the metastatic site in 21 patients with MBC, after excluding the stage IV case, the AI intake period was significantly longer in patients with ESRI mutation than in those without ESRI mutation ( 5 vs. 0 months; $\mathrm{P}=0.04$; Table IV). However, there were no significant differences in the treatment period with SERM or AI/ SERM between patients with and without ESRI mutation $(\mathrm{P}=0.83$ and $\mathrm{P}=0.05$, respectively).

The age at the time of treatment initiation was significantly lower in patients with mutant ESRI compared with that in patients without mutant $E S R l(49 \pm 11$ vs. $63 \pm 12$ years; $\mathrm{P}=0.01$; Table IV). There were no significant differences in the primary TNM stage, histologic type, PgR and HER 2 status of primary tumor between the two patient groups. The number of administered ETs tended to be higher in patients with ESRI mutation compared with that in those without ESRI mutation, but the difference was not significant ( 1.5 vs. 0 , respectively; $\mathrm{P}=0.06$; Table IV). The number of ETs administered to the patients from recurrence to biopsy was not significantly different between the two patient groups ( 1 vs. $0 ; \mathrm{P}=0.10)$. The age at the time of the initiating treatment was associated with the SERM intake period (Spearman's rank correlation coefficient, -0.45; P=0.03; Table IV).

\section{Discussion}

In the present study on a cohort of patients with $\mathrm{MBC}$, the presence of LBD mutations in the ESRI gene was detected by targeted NGS, and its association with patient clinicopathologic characteristics was assessed. The frequency of ESR 1 mutations in metastatic samples was $64 \%$ in this study and varied between 13 and 55\% among published studies that also used NGS (14-16,26). Compared with previous studies, 
Table III. ESRI mutations and the clinical data of 22 patients with metastatic breast cancer.

\begin{tabular}{|c|c|c|c|c|c|c|}
\hline Case no. & $\begin{array}{l}\text { Age, } \\
\text { years }^{\mathrm{a}}\end{array}$ & Mutations & Allred of $\mathrm{E} / \mathrm{P}^{\mathrm{b}}$ & Biopsy site & $\begin{array}{c}\text { Adjuvant ET } \\
\text { (months, status) }\end{array}$ & $\begin{array}{l}\text { ET after recurrence } \\
\text { to biopsy }\end{array}$ \\
\hline 1 & 74 & Yes & $7 / 0$ & Skin & AI (21, incomplete) & None \\
\hline 2 & 48 & Yes & $8 / 8$ & Liver & SERM $(60$, complete $)$ & AI, SERD, AI \\
\hline 3 & 51 & Yes & $7 / 7$ & Skin & AI (7), SERM (53, complete) & None \\
\hline 4 & 35 & Yes & $8 / 8$ & LN & None & None \\
\hline 5 & 30 & Yes & $7 / 5$ & LN & None & AI, SERM, AI, SERD \\
\hline 6 & 56 & Yes & Unavailable & Bone & AI $(60$, complete $)$ & AI \\
\hline 7 & 54 & Yes & $8 / 7$ & Skin & SERM (60, complete) & None \\
\hline 8 & 47 & Yes & $7 / 0$ & Liver & SERM (22, incomplete) & AI, SERD \\
\hline 9 & 54 & Yes & $8 / 6$ & Skin & SERM (60, complete) & AI \\
\hline 10 & 39 & Yes & $8 / 8$ & Liver & SERM (24, incomplete) & AI, AI \\
\hline 11 & 51 & Yes & $8 / 8$ & Liver & SERM (24, complete) & None \\
\hline 12 & 57 & Yes & $8 / 7$ & Liver & SERM (60, complete) & AI \\
\hline 13 & 42 & Yes & $8 / 5$ & Skin & SERM (37, incomplete) & None \\
\hline 14 & 46 & Yes & $8 / 8$ & Liver & None & AI, AI \\
\hline 15 & 74 & No & $8 / 8$ & Skin & AI (60, complete) & None \\
\hline 16 & 75 & No & $8 / 8$ & Muscle & None & None \\
\hline 17 & 58 & No & $8 / 6$ & LN & AI $(60$, complete $)$ & None \\
\hline 18 & 39 & No & $8 / 0$ & LN & SERM ( 23, incomplete) & None \\
\hline 19 & 59 & No & $8 / 8$ & Lung & None & AI, SERM \\
\hline 20 & 63 & No & $7 / 7$ & Lung & AI $(58$, incomplete $)$ & None \\
\hline 21 & 60 & No & $8 / 0$ & Liver & AI $(60$, complete $)$ & None \\
\hline 22 & 74 & No & $8 / 5$ & Lung & None & None \\
\hline
\end{tabular}

${ }^{\mathrm{a}} \mathrm{Age}$ at the start of treatment. ${ }^{\mathrm{b}} \mathrm{Allred}$ score of $\mathrm{E} / \mathrm{P}$ at metastasis. ${ }^{\mathrm{c}}$ The patient had stage IV breast cancer. Incomplete adjuvant setting is defined as the recurrence of breast cancer during adjuvant treatment. E/P, estrogen receptor/progesterone receptor; ESRl, estrogen receptor 1; ET, endocrine treatment; AI, aromatase inhibitor; SERM, selective estrogen receptor modulator; SERD, selective estrogen receptor degrader; LN, lymph node; PgR, progesterone receptor.

the present study had a higher frequency of ESRl mutations and a lower number of administered ETs. This study demonstrated that there was no association between the number of administered ET and the development of ESRI mutation. Two previous studies have demonstrated an association between ET exposure and the prevalence of mutated ESRI $(26,27)$, although the number of previously administered ET was not clarified.

In the current study, the ESR1 mutations Leu536Arg, Tyr537Ser, Glu542Asp and Arg548Cys were detected. The Tyr537Ser and Arg548Cys mutations have been demonstrated to induce estrogen-independent activity of the ER, leading to ET resistance $(15,28)$. In addition, bioinformatics analysis has indicated that an Arg548Cys mutation in the ER is deleterious (29). Similarly, amino acid mutations in Leu536 have been reported to increase the estrogen-independent activity of the ER (30), and Toy et al (15) identified the Leu536Arg mutation in the ER, but they did not investigate its function. The impact of the Glu542Asp alteration on the ER function remains unknown and further investigation is needed (31). Therefore, the detected ER mutations in this study, with the exception of Glu542Asp, may induce a ligand-independent ER activation resulting in ET resistance. It is important to deter- mine the changes of ESRI alterations between primary and metastatic tumor; however, in this study, the ESR 1 mutations of the primary lesion were not investigated because primary breast cancers have very rare ESRI mutation, which has been reported in previous studies, including The Cancer Atlas data (32-34).

A number of previous studies on patients with MBC have demonstrated that compared with wild-type ESR1, ESR1 mutation led to worse progression-free survival (PFS) and overall survival (OS) $(35,36)$. However, in the present study, ESR I mutation had no adverse impact on the outcomes of patients with MBC (data not shown). The small cohort used in the present study limited the statistical power to assess the impact on the outcomes of patients with MBC.

This may be due to the Glu542Asp mutation, which was detected in 2 patients with MBC in this study, having no negative effect on the patients' outcomes. The present study revealed that prolonged AI treatment for metastasis had a significant impact on the development of ESR I mutation and that patients with $\mathrm{MBC}$ who received AIs in an adjuvant setting exhibited low rates of ESRI mutation. A number of previous studies reported that mutated ESRI rarely occurred during adjuvant therapy with AI, but its prevalence was high 
Table IV. Association between estrogen receptor 1 gene mutation and clinicopathologic data in 22 patients with metastatic breast cancer.

A, According to the total duration from the beginning of treatment to biopsy of the metastatic site $(n=22)$

\begin{tabular}{|c|c|c|c|}
\hline Variable & Mutation (+) & Mutation (-) & P-value \\
\hline AI & $15(0-83)$ & $31(0-60)$ & 0.92 \\
\hline SERM & $26(0-60)$ & $0(0-23)$ & 0.01 \\
\hline AI + SERM & $60(0-143)$ & $41(0-60)$ & 0.13 \\
\hline
\end{tabular}

$B$, According to the total duration from recurrence to biopsy of the metastatic site $(n=21)$

\begin{tabular}{|c|c|c|c|}
\hline Variable & Mutation (+) & Mutation (-) & P-value \\
\hline AI & $5(0-83)$ & $0(0-3)$ & 0.04 \\
\hline SERM & $0(0-27)$ & $0(0-7)$ & 0.83 \\
\hline $\mathrm{AI}+\mathrm{SERM}$ & $5(0-83)$ & $0(0-10)$ & 0.05 \\
\hline
\end{tabular}

C, According to clinicopathological characteristics $(n=22)$

\begin{tabular}{|c|c|c|c|}
\hline Variable & Mutation (+) & Mutation (-) & P-value \\
\hline Age at the start of treatment, years & $49 \pm 11$ & $63 \pm 12$ & 0.01 \\
\hline \multicolumn{4}{|l|}{ Primary TNM stage } \\
\hline $\mathrm{I}$ & 4 & 3 & \\
\hline IIA & 5 & 4 & \\
\hline IIB & 3 & 1 & \\
\hline IIIA & 0 & 0 & \\
\hline IIIB & 1 & 0 & \\
\hline IIIC & 0 & 0 & \\
\hline IV & 1 & 0 & \\
\hline \multicolumn{4}{|l|}{ Histological type } \\
\hline Invasive ductal & 13 & 8 & \\
\hline Invasive lobular & 1 & 0 & $>0.99$ \\
\hline \multicolumn{4}{|l|}{ PgR status of the primary tumor } \\
\hline Positive & 13 & 8 & \\
\hline Negative & 1 & 0 & $>0.99$ \\
\hline \multicolumn{4}{|l|}{ HER2 status of the primary tumor } \\
\hline Positive & 2 & 2 & \\
\hline Negative & 11 & 6 & 0.62 \\
\hline Total number of administered $\mathrm{ET}^{\mathrm{a}}$ & $1.5(0-3)$ & $1(0-1)$ & 0.06 \\
\hline The number of ET from recurrence to biopsy & $1(0-3)$ & $0(0-2)$ & 0.10 \\
\hline Spearman's rank correlation & \multicolumn{2}{|c|}{ Coefficient } & \\
\hline Age at the start of treatment vs. & \multicolumn{2}{|c|}{-0.45} & 0.03 \\
\hline
\end{tabular}

${ }^{a}$ Excluding SERD regimen. Values are expressed as the median (range) or the mean \pm standard deviation and analyzed by Wilcoxon rank sum test, independent samples Student's t-test or Fisher's exact test. AI, aromatase inhibitor; SERM, selective estrogen receptor modulator; TNM, Tumor-Node-Metastasis; PgR, progesterone receptor; ET, endocrine treatment.

during recurrence treatment with AI $(17,35)$. The results of the present study appeared to support these studies. Previous studies have also demonstrated the superior effects of fulvestrant on the PFS and OS compared with those of anastrozole in patients with endocrine-sensitive $\operatorname{MBC}(37,38)$. Furthermore, the addition of palbociclib, a CDK4/6 inhibitor, 
to letrozole or fulvestrant improved the PFS in patients with MBC $(39,40)$. Of note, it was reported that palbociclib combined with fulvestrant improved the PFS irrespective of the ESR1 mutation status in patients with MBC (41) and that palbociclib plus letrozole did not prevent the development of ESR I mutation in a small cohort of patients with MBC who received the combination treatment (42). These results suggest that the assessment of dynamic changes of the ESR 1 mutation status using minimally invasive procedures such as liquid biopsy in patients with $\mathrm{MBC}$ who receive CDK4/6 inhibitors may be of importance for investigating acquired resistance to these drugs.

The results of the present study demonstrated that the total period of SERM treatment was associated with the emergence of ESR 1 mutation. To the best of our knowledge, the effects of SERM on ESRl mutation have not been fully clarified to date. Among patients with $\mathrm{MBC}$ who received tamoxifen alone, ESRI mutation was not detected in all 22 patients in a study by Schiavon et al (17), but it was detected in 4 out of 11 patients in a study by Takeshita et al (43). The present study demonstrated that the frequency rate of ESRI alteration in patients who received adjuvant-SERM followed by metastatic AI treatment was higher compared with that in patients who received no adjuvant-SERM followed by metastatic AI. The association of SERM with ESRl mutation that was identified in this study may be explained by the finding that most of the patients with mutated ESR who received AIs for metastasis had been administered SERMs in an adjuvant setting. Administration of SERM in an adjuvant setting may have been used as a compelling indication for the use of AI for metastasis; therefore, SERM for adjuvant setting, followed by AI for metastasis, may increase the frequency of ESRI mutations. However, this result needs to be clarified and verified in a future study.

The present study revealed that age at the time of treatment initiation for breast cancer was significantly associated with the development of ESR 1 mutation and the total duration of SERM treatment. These associations may be due to the premenopausal status of the majority of patients with MBC who received SERM in an adjuvant setting and AI in a metastatic setting, leading to the subsequent development of ESRI mutation. To the best of our knowledge, no previous studies have demonstrated an association between age at the time of treatment initiation for breast cancer and the occurrence of ESR1 gene mutation.

This study had several limitations, including the retrospective design using a small cohort from a single institute. In addition, the effects of SERD on ESRI mutations were not analyzed, as only three patients with MBC received SERD, and no multivariate analysis was performed due to the small cohort. The small cohort of this study limited the statistical power to assess the association between ESRI mutation and clinicopathological features in patients with MBC.

In conclusion, the results of the present study demonstrated that SERM in an adjuvant setting followed by AI for metastasis may increase the frequency of ESRI mutation, and that age at the time of treatment onset for breast cancer may be significantly associated with the development of ESRI mutation. Further studies are needed to confirm and validate these findings.

\section{Acknowledgements}

The authors would like to thank Mr. Kazuhiro Miyao at the Department of Surgery, Keio University School of Medicine (Tokyo, Japan) for his excellent technical assistance and helpful insights on DNA extraction and next generation sequencing.

\section{Funding}

The present study was supported by a grant-in-aid from the Japan Society for the Promotion Science (grant no. 16K10474 to MT).

\section{Availability of data and materials}

The datasets used and/or analyzed during the present study are available from the corresponding author on reasonable request.

\section{Authors' contributions}

KT, TH, TS, MT and YK conceived and designed this study. $\mathrm{HM}, \mathrm{AN}$ and TY performed the experiments and collected clinical data from the patients. KT analyzed data and drafted the manuscript. All authors revised the manuscript and approved the final version.

\section{Ethics approval and consent to participate}

The study protocol, including the opt-out informed consent procedure, was approved by the Ethics Review Board of Keio University Hospital (approval no. 20150439) and conformed to Declaration of Helsinki.

\section{Patient consent for publication}

Not applicable.

\section{Competing interests}

TH and YK received lecture fee and research funding from Pfizer Inc., Novartis Pharma K.K., and AstraZeneca. All other authors confirm that they have no competing interests.

\section{References}

1. Olefsky JM: Nuclear receptor minireview series. J Biol Chem 276: 36863-36864, 2001

2. Gianluca A, Flavia P and Paolo M: Update on Mechanisms of Hormone Action: Focus on Metabolism, Growth and Reproduction. Tech, Rijeka, Croatia, pp71-73, 2011.

3. Tamoxifen for early breast cancer: An overview of the randomised trials. Early Breast Cancer Trialists' Collaborative Group. Lancet 351: 1451-1467, 1998.

4. Ruff M, Gangloff M, Wurtz JM and Moras D: Estrogen receptor transcription and transactivation: Structure-function relationship in DNA- and ligand-binding domains of estrogen receptors. Breast Cancer Res 2: 353-359, 2000.

5. Kojetin DJ, Burris TP, Jensen EV and Khan SA: Implications of the binding of tamoxifen to the coactivator recognition site of the estrogen receptor. Endocr Relat Cancer 15: 851-870, 2008.

6. Heldring N, Pike A, Andersson S, Matthews J, Cheng G, Hartman J, Tujague M, Ström A, Treuter E, Warner M and Gustafsson JA: Estrogen receptors: How do they signal and what are their targets. Physiol Rev 87: 905-931, 2007. 
7. Goldhirsch A, Glick JH, Gelber RD, Coates AS and Senn HJ: Meeting highlights: International Consensus Panel on the Treatment of Primary Breast Cancer. Seventh International Conference on Adjuvant Therapy of Primary Breast Cancer. J Clin Oncol 19: 3817-3827, 2001.

8. Pritchard KI: Endocrine therapy: Is the first generation of targeted drugs the last? J Intern Med 274: 144-152, 2013.

9. Osborne CK, Bardou V, Hopp TA, Chamness GC, Hilsenbeck SG, Fuqua SA, Wong J, Allred DC, Clark GM and Schiff R: Role of the estrogen receptor coactivator AIB1 (SRC-3) and HER-2/neu in tamoxifen resistance in breast cancer. J Natl Cancer Inst 95: 353-361, 2003.

10. Schiff R, Massarweh SA, Shou J, Bharwani L, Mohsin SK and Osborne CK: Cross-talk between estrogen receptor and growth factor pathways as a molecular target for overcoming endocrine resistance. Clin Cancer Res 10 (Suppl): S331-S336, 2004.

11. Zhou Y, Yau C, Gray JW, Chew K, Dairkee SH, Moore DH Eppenberger U, Eppenberger-Castori S and Benz CC: Enhanced NF kappa B and AP-1 transcriptional activity associated with antiestrogen resistant breast cancer. BMC Cancer 7: 59, 2007.

12. Thangavel C, Dean JL, Ertel A, Knudsen KE, Aldaz CM, Witkiewicz AK, Clarke R and Knudsen ES: Therapeutically activating RB: Reestablishing cell cycle control in endocrine therapy-resistant breast cancer. Endocr Relat Cancer 18: 333-345, 2011.

13. Witkiewicz AK and Knudsen ES: Retinoblastomatumor suppressor pathway in breast cancer: Prognosis, precision medicine, and therapeutic interventions. Breast Cancer Res 16: 207, 2014.

14. Robinson DR, Wu YM, Vats P, Su F, Lonigro RJ, Cao X, Kalyana-Sundaram S, Wang R, Ning Y, Hodges L, et al: Activating ESR1 mutations in hormone-resistant metastatic breast cancer. Nat Genet 45: 1446-1451, 2013.

15. Toy W, Shen Y, Won H, Green B, Sakr RA, Will M, Li Z, Gala K, Fanning S, King TA, et al: ESR1 ligand-binding domain mutations in hormone-resistant breast cancer. Nat Genet 45: 1439-1445, 2013.

16. Merenbakh-Lamin K, Ben-Baruch N, Yeheskel A, Dvir A, Soussan-Gutman L, Jeselsohn R, Yelensky R, Brown M, Miller VA, Sarid D, et al: D538G mutation in estrogen receptor- $\alpha$ : A novel mechanism for acquired endocrine resistance in breast cancer. Cancer Res 73: 6856-6864, 2013.

17. Schiavon G, Hrebien S, Garcia-Murillas I, Cutts RJ, Pearson A, Tarazona N, Fenwick K, Kozarewa I, Lopez-Knowles E, Ribas R, et al: Analysis of ESR1 mutation in circulating tumor DNA demonstrates evolution during therapy for metastatic breast cancer. Sci Transl Med 7: 313ra182, 2015.

18. Reinert T, Saad ED, Barrios CH and Bines J: Clinical implications of ESR 1 mutations in hormone receptor-positive advanced breast cancer. Front Oncol 7: 26, 2017.

19. Allred DC, Harvey JM, Berardo M and Clark GM: Prognostic and predictive factors in breast cancer by immunohistochemical analysis. Mod Pathol 11: 155-168, 1998.

20. Li H and Durbin R: Fast and accurate short read alignment with Burrows-Wheeler transform. Bioinformatics 25: 1754-1760, 2009.

21. Li H, Handsaker B, Wysoker A, Fennell T, Ruan J, Homer N, Marth G, Abecasis G and Durbin R; 1000 Genome Project Data Processing Subgroup: The Sequence Alignment/Map format and SAMtools. Bioinformatics 25: 2078-2079, 2009.

22. DePristo MA, Banks E, Poplin R, Garimella KV, Maguire JR, Hartl C, Philippakis AA, del Angel G, Rivas MA, Hanna M, et al: A framework for variation discovery and genotyping using next-generation DNA sequencing data. Nat Genet 43: 491-498, 2011.

23. Cingolani P, Platts A, Wang le L, Coon M, Nguyen T, Wang L, Land SJ, Lu X and Ruden DM: A program for annotating and predicting the effects of single nucleotide polymorphisms, SnpEff: SNPs in the genome of Drosophila melanogaster strain w1118; iso-2; iso-3. Fly (Austin) 6: 80-92, 2012

24. Robinson JT, Thorvaldsdóttir H, Winckler W, Guttman M, Lander ES, Getz $\mathrm{G}$ and Mesirov JP: Integrative genomics viewer. Nat Biotechnol 29: 24-26, 2011.

25. Kanda Y: Investigation of the freely available easy-to-use software 'EZR' for medical statistics. Bone Marrow Transplant 48: 452-458, 2013.

26. Jeselsohn R, Yelensky R, Buchwalter G, Frampton G, Meric-Bernstam F, Gonzalez-Angulo AM, Ferrer-Lozano J, Perez-Fidalgo JA, Cristofanilli M, Gómez H, et al: Emergence of constitutively active estrogen receptor- $\alpha$ mutations in pretreated advanced estrogen receptor-positive breast cancer. Clin Cancer Res 20: 1757-1767, 2014.

27. Takeshita T, Yamamoto Y, Yamamoto-Ibusuki M, Tomiguchi M, Sueta A, Murakami K, Omoto Y and Iwase H: Comparison of ESR1 mutations in tumor tissue and matched plasma samples from metastatic breast cancer patients. Transl Oncol 10: 766-771, 2017.
28. Li B, Liu L, Fu X, Zhou WQ, Zou DT, Zhao XY, Cai YN, Tu HB, Liu QC and Chen YY: A novel mutation of estrogen receptor gene detected in girls with precocious puberty. Yi Chuan Xue Bao 32: 1011-1017, 2005.

29. Rebaï M and Rebaï A: In silico characterization of functional SNP within the oestrogen receptor gene. J Genet 95: 865-874, 2016.

30. Zhao C, Koide A, Abrams J, Deighton-Collins S, Martinez A, Schwartz JA, Koide S and Skafar DF: Mutation of Leu-536 in human estrogen receptor-alpha alters the coupling between ligand binding, transcription activation, and receptor conformation. J Biol Chem 278: 27278-27286, 2003.

31. Chung JH, Pavlick D, Hartmaier R, Schrock AB, Young L, Forcier B, Ye P, Levin MK, Goldberg M, Burris H, et al: Hybrid capture-based genomic profiling of circulating tumor DNA from patients with estrogen receptor-positive metastatic breast cancer. Ann Oncol 28: 2866-2873, 2017.

32. Karnik PS, Kulkarni S, Liu XP, Budd GT and Bukowski RM: Estrogen receptor mutations in tamoxifen-resistant breast cancer. Cancer Res 54: 349-353, 1994.

33. Roodi N, Bailey LR, Kao WY, Verrier CS, Yee CJ, Dupont WD and Parl FF: Estrogen receptor gene analysis in estrogen receptor-positive and receptor-negative primary breast cancer. J Natl Cancer Inst 87: 446-451, 1995.

34. Cancer Genome Atlas Network: Comprehensive molecular portraits of human breast tumours. Nature 490: 61-70, 2012.

35. Chandarlapaty S, Chen D, He W, Sung P, Samoila A, You D, Bhatt T, Patel P, Voi M, Gnant M, et al: Prevalence of ESR1 mutations in cell-free DNA and outcomes in metastatic breast cancer: A secondary analysis of the BOLERO-2 clinical trial. JAMA Oncol 2: 1310-1315, 2016

36. Clatot F, Perdrix A, Augusto L, Beaussire L, Delacour J, Calbrix C, Sefrioui D, Viailly PJ, Bubenheim M, Moldovan C, et al: Kinetics, prognostic and predictive values of ESR1 circulating mutations in metastatic breast cancer patients progressing on aromatase inhibitor. Oncotarget 7: 74448-74459, 2016.

37. Robertson JFR, Bondarenko IM, Trishkina E, Dvorkin M, Panasci L, Manikhas A, Shparyk Y, Cardona-Huerta S, Cheung KL, Philco-Salas MJ, et al: Fulvestrant $500 \mathrm{mg}$ versus anastrozole $1 \mathrm{mg}$ for hormone receptor-positive advanced breast cancer (FALCON): An international, randomised, double-blind, phase 3 trial. Lancet 388: 2997-3005, 2016.

38. Ellis MJ, Llombart-Cussac A, Feltl D, Dewar JA, Jasiówka M, Hewson N, Rukazenkov Y and Robertson JF: Fulvestrant 500 mg versus anastrozole $1 \mathrm{mg}$ for the First-line treatment of advanced breast cancer: Overall survival analysis from the phase II FIRST study. J Clin Oncol 33: 3781-3787, 2015.

39. Finn RS, Crown JP, Lang I, Boer K, Bondarenko IM, Kulyk SO, Ettl J, Patel R, Pinter T, Schmidt M, et al: The cyclin-dependent kinase 4/6 inhibitor palbociclib in combination with letrozole versus letrozole alone as first-line treatment of oestrogen receptor-positive, HER2-negative, advanced breast cancer (PALOMA-1/TRIO-18): A randomised phase 2 study. Lancet Oncoly 16: 25-35, 2015.

40. Turner NC, Ro J, André F, Loi S, Verma S, Iwata H, Harbeck N, Loibl S, Huang Bartlett C, Zhang K, et al: Palbociclib in hormone-receptor-positive advanced breast cancer. N Engl J Med 373: 209-219, 2015.

41. Fribbens C, O'Leary B, Kilburn L, Hrebien S, Garcia-Murillas I, Beaney M, Cristofanilli M, Andre F, Loi S, Loibl S, et al: Plasma ESR 1 mutations and the treatment of estrogen receptor-positive advanced breast cancer. J Clin Oncol 34: 2961-2968, 2016.

42. Gyanchandani R, Kota KJ, Jonnalagadda AR, Minteer T, Knapick BA, Oesterreich S, Brufsky AM, Lee AV and Puhalla SL: Detection of ESR1 mutations in circulating cell-free DNA from patients with metastatic breast cancer treated with palbociclib and letrozole. Oncotarget 8: 66901-66911, 2016.

43. Takeshita T, Yamamoto Y, Yamamoto-Ibusuki M, Inao T, Sueta A, Fujiwara S, Omoto Y and Iwase H: Droplet digital polymerase chain reaction assay for screening of ESR1 mutations in 325 breast cancer specimens. Transl Res 166: 540-553.e2, 2015.

This work is licensed under a Creative Commons Attribution-NonCommercial-NoDerivatives 4.0 International (CC BY-NC-ND 4.0) License. 